\begin{tabular}{c} 
Volume and Issues Obtainable at Center for Sustainability Research and Consultancy \\
Journal of Business and Social Review in Emerging Economies \\
ISSN: 2519-089X \& ISSN (E): 2519-0326 \\
Volume 7: Issue 2 June 2021 \\
CSRᄃ \\
Journal homepage: www.publishing.globalcsrc.org/jbsee \\
\hline
\end{tabular}

\title{
Empowering Pakistani Woman: Impact of Education, Technology and Training Skills Development
}

*Noreen Sharif, Lecturer, Management Sciences, National University of Modern Languages (NUML), Hyderabad, Pakistan

Noreen Hassan, Lecturer, Business Administration, Federal Urdu University of Arts Science \& Technology (FUUAST), Karachi, Pakistan

Shelomith Angel, Lecturer, Management Sciences, National University of Modern Languages

(NUML), Hyderabad, Pakistan

*Corresponding author's email: noureenshareef@numl.edu.pk

ARTICLE DETAILS
History
Revised format: May 2021

Available Online: Jun 2021

Keywords
Woman empowerment,
education, technology
facilitation, training \&
skills development

JEL Classification

M11, M12

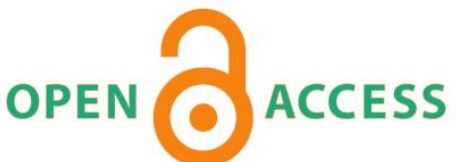

\section{ABSTRACT}

Purpose: It is known fact that currently Pakistani woman are facing several problems e.g., domestic violence, gender dominancy, gender discrimination and unequal distribution of power, rights and work, due the inadequacy of education. In this contemporary era of gender inequality woman empowerment is an essential area of study to be focused on. This study, therefore, aims to investigate the impact of education, technology and Skills development adopted for empowerment of women.

Design/Methodology/Approach: Data was collected from private and government girls' colleges of Hyderabad district Sindh. A survey technique was used to collect data using convenience non random sampling technique. Smart PLS responses analyzed with the sample size of 1184 .

Findings: Results of Structural equation modeling through Smart PLS supported the structural model. It was found that appropriate educational facilities, technology facilitation and training and skills development positively related to Pakistani woman empowerment.

\section{Implications/Originality/Value:}

Education is the milestone in empowering woman and the main factor in woman's prosperity and development. In this scenario, education is a turning point in playing vital role in empowering woman because it enables the woman to face the challenges of contemporary time and make a significant change in their traditional roles and in their lives. Academician, policy makers and leaders of organizations must note this fact.

(C) 2021 The authors, under a Creative Commons AttributionNonCommercial 4.0 
Recommended citation: Sharif, N., Hassan, N., Angel, S. and Tariq, U.(2021). Empowering Pakistani woman: Impact of education, technology and training skills development. Journal of Business and Social Review in Emerging Economies, 7(2), 433-441.

\section{Introduction}

In this contemporary era of gender inequality woman empowerment is an essential area of study to be focused on. Women's empowerment is certainly obligatory in the societies as it upsurge woman self-esteem and contribute in the whole society, nation and the world. Assuming their equal right to participate in education, society, economy and politically. Thus, woman empowerment is accepting the rights of woman by giving them recognition, understanding their valuable and distinguishing participation and well appreciated struggles (Ali, 2015).

Due Half of humans comprises of woman, but the literacy rate of women is lower than the man's literacy rate. The literacy level of women is affected by the discrimination, gender inequality and society's set traditions which are hurdles in woman access to get education. Education is the key to woman success empowerment to survive in the male dominating society. Women must strengthen its position to fight against the gender bias constructed by society. Women education is the most important need of the contemporary time \& women should be considered equally competent no matter in outside the world or behind the veil (Tunio, 2015). Where the women education can be enhanced by empowering them educationally, socially and legally (Ojha, 2016). Education is a systematic process of providing skills, knowledge and experience to enhance a human force, that is the major requirement of society(Ali, 2015).

In Pakistan, the literacy rate is extremely poor and insignificant as compare to other developing countries. In general, country is comparatively more developed in the demographic, cultural, and health-nutrition indicators but is less progressed in housing, academics and political domain (Tunio, 2015). Thus, Pakistan has overlooked education sector which is major ingredient and indictor for the success and development of modernized world (Khan \& Zerby, 1981). The Pakistan Economic Survey 2018-2019 revealed 60\% where the percentage for male remains $58 \%$ whereas female found $49 \%$ (Rehman, Jingdong, \& Hussain, 2015). For the rapid economic growth there is need develop education institutions and empower the women by providing improved education facilities and appropriate infrastructure (News, 2020).

Women are empowered by help resources, awareness, unbiased policies and facilities are also need ed by higher authorities (Fernandes, 2015). This study is unique as it highlights the issues of educational barriers faced by women to get education and ways to resolve poverty issues faced by Hyderabad district Sindh women. This Study helps gain imperative insight for the policy makers, academicians and governing bodies in Pakistan to provide a way forward for mitigating gender disparity and establishing productive initiatives for empowering women. Education provides a foundation for development, the groundwork on which much of our economic and social wellbeing is built. It is the key to increasing economic efficiency and social consistency. By increasing the value and efficiency of their labor, it helps to raise the poor from poverty. Education is key towards the reduction of gender disparities (Umair, 2016).

\section{Hypothesis Development}

\section{Educational Facilities and Women Empowerment}

Empowerment can be seen as a means of creating a social environment in which decision-making and social change decisions can be made individually or collectively. Woman empowerment is termed as, a power to a woman where she is free to make her decisions because empowerment stands for that multidimensional phenomenon that enables one to have authority of their own lives(Correa-fernandes, 2015).

Formal education is the learning that takes place in everyday life. Naturally, informal educators le 
arned from relatives, societies and their friends and, on the other hand, formal education is neede $\mathrm{d}$ to empower the individual with certain special skills that distinguish them in society(ambreen, 2013). Study indicated since women empowerment is an energetic and dynamic process that facilitates them to realize their identity and power in all characteristics. Due to the lack of educational facilities, and less focus to equip them with appropriate academic qualification; women have ignorance towards their rights. As a result their positive participation in society is below average (Ojha, 2016). In the similar context (M. Ahmed, Zameer, Verman, \& Godiyal, 2021) revealed the educational barriers faced by girls to approach basic education results imbalances in their life and society. Investing in their futures has the potential to uplift their families and reduce poverty.

The study would indicate the approach to fundamental education rural and urban schools in Pakistani context. Since in rural areas parents reluctant to send their children to school. Thus are due to absence of resources, incompetent teachers, lack of facilities for female students. Thus, study highlighted the education system weaknesses and suggested ways to be incorporated to empower the rural as well as urban region woman (Saeeda Shah, 2012). Additionally, an educated woman cannot be exploited as easily, as she knows and is aware of her individuality and rights. She will not be easily suppressed. Education of women can also help in eradicating many social evils such as dowry problems that plague all parents, unemployment problem and others (Yerriswamye, 2016). An Indian study revalued the poor situation, where educational hurdles are not only created by male members but also female senior's members of their society remain opposed to girls education. Although up to some extent these barriers were overcome by many NGOs and governmental interventions. Lack of education is the main obstacle to growth and empowerment. The rate of literacy is high in rural areas especially among women education. Women's education is critical in rural areas of India comparatively urban areas of India(Tunio, 2015).

Therefore, on the ground of the preceding studies, it is hypothesized that:

H1: Educational facilities positively related to woman empowerment

\section{Technology Facilitation and Training \& Skills Development and Women Empowerment}

Is shown the reason behind failure to woman participation in growth and progress in the country in Saudi Context (Ojha, 2016). It reveal due to access to technology like internet, computer or other multimedia sort of equipment's, lack of training for instance leadership, team working, developing self-esteem and personality development, communication skills and less provision of supportive administrative structure to empower woman. The study further indicated success of countries depend upon whole nation but due to lack of equitable and inclusive participation of women the process work slow. If women engaged in economic activity on the same level as men, results clear economic and social benefits. Another study highlighted rural areas women who are lacking in educational as well as vocational training facilities suffers a lot and unable to improve their livelihood. Due to this shortage the employment opportunities and financially resources enhancement impossible. Education and training equally important for all. Well skilled manpower not only contributed positively to economic growth, but to improved quality labour market and improves the standards of living of the society in general since skillful labour would tend to have quality jobs and high wages compared to unskilled labour (Mulhim, 2013).

The finding endorsed similar positive association between Technology facilitation and training \& skills development and Women empowerment in Nigeria. It was found that the major difficulties of Technology facilitation and training \& skills development for sustainable empowerment were inadequate training facilities and acute shortage of trained qualified instructors and trainers. Thus, at the extend governmental as well as private support sector participation in essentials to equipped woman (Memon, 2007). 
The study found positive relationship between Technical and Vocational Education and Training and women empowerment in rural and urban areas of Pakistani context. The finding reveals since Rural women are found to get less economic benefits of jobs and income earnings as compared to their urban people (Okolie et al., 2020).

Therefore, on the ground of the preceding studies, it is hypothesized that:

\section{H2: Technology Facilitation positively related to woman empowerment H3: Training and Skills Development positively related to woman empowerment}

Fig-1 indicate conceptual frame work

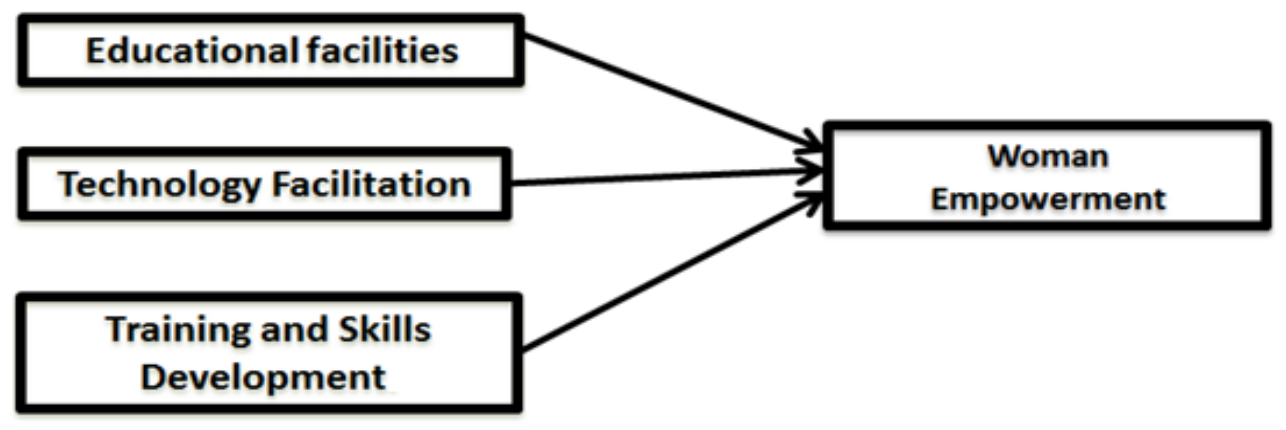

Figure-I Conceptual Framework

Source: Researcher

\section{Materials and Methods}

The quantitative based research methodology a general survey has been conducted in this study that includes questionnaire which were distributed among the private and government girls' colleges of Hyderabad district Sindh. A well-structured cross-sectional questionnaire is used which consists of twenty four items. All the adapted instrumentare pre- tested. Questionnaires were distributed to the girls' students of both public and private Colleges situated in Hyderabad district Sindh.

For the study a convenience non-random sampling techniques is applied where to get the minimum sample size. To find out the sample size $G^{*}$ power software version 3.1.9.2 (A. Ahmed, Wadood, \& Mohammad, 2020) is used that results 132 as minimum sample size. Total 1400 questionnaire have given to students from the population of Hyderabad district girl's private and public colleges, out of which 1184 were received where 646 are taken from of public girl's colleges and 538 are taken from private girl's colleges. Therefore, the return rate is $85 \%$ of the original sample. The survey questionnaires initial part consists of demographic details of the respondents while lateral part comprises of 24 items with five point Likert scale . In this study 5point Likert scale comprises of extending (1-5) strongly agree to strongly disagree is incorporate in the questionnaire. Negative/reverse coded questions are the portion of questionnaire so the employees could response with concern. Following are the parts of questionnaire. Educational facilities (EF) measured using 5-items instrument by (Faul, Erdfelder, Lang, \& Buchner, 2007). The items included for example "I am generally comfortable when communicating with my teachers," technology facilitation (TF) using the 4- items scale adopted from the study of (Plax, Kearney, \& Downs, 1986). Examples of the items are: "the technology necessary (computers, cables, modems, etc) for the internet use in my institute are modern and updated", "I have good and quick access of the Internet facility at my institution." However, training and skills development (TSD) tested using 3-items scale by (Taylor \& Todd, 1995)is used. Examples of the questions included are: "I am given a real opportunity to improve my skills in this institution" and "this institution has a well-defined training and skills development programmes." While woman empowerment (WEMP) with the 12-items scale by (Gaertner \& Nollen, 1989)is used. 
Examples of the items included, "I have influence over what happens in my work" and "I am confident about my ability to do my job"

\section{Data Analysis}

Using structural equation modeling (SEM) Spreitzer (1995) the data analysis has been done. In measurement model analysis, the table- 1 shows that the outer loadings are satisfactory indicating above 0.50 which reflect the reliability of the indicators (Hair, Sarstedt, Hopkins, \& Kuppelwieser, 2014; Ringle, Wende, \& Becker, 2015). The composite reliability values are above than the suggested value of 0.7 which establishes internal consistency reliability (Hair, Sarstedt, Ringle, \& Gudergan, 2017).As per suggestion (Hair, Black, Babin, Anderson, \& Tatham, 2006) the AVE larger than 0.5 indicating convergent validity has been established

Table-1 Outer Loadings, Composite Reliability and Average Variance Extracted

\begin{tabular}{|c|c|c|c|c|}
\hline Construct & Items & $\begin{array}{l}\text { Outer } \\
\text { Loadings }\end{array}$ & $\begin{array}{l}\text { Composite Reliability } \\
\text { (CR) }\end{array}$ & $\begin{array}{l}\text { Average Variance } \\
\text { (AVE) }\end{array}$ \\
\hline \multirow{5}{*}{ Educational Facilities (EF) } & EF1 & 0.74 & \multirow{5}{*}{0.868} & \multirow{5}{*}{0.569} \\
\hline & EF2 & 0.78 & & \\
\hline & EF3 & 0.79 & & \\
\hline & EF4 & 0.72 & & \\
\hline & EF5 & 0.74 & & \\
\hline \multirow{4}{*}{ Technology Facilitation (TF) } & TF1 & 0.79 & \multirow{4}{*}{0.877} & \multirow{4}{*}{0.641} \\
\hline & TF2 & 0.82 & & \\
\hline & TF3 & 0.75 & & \\
\hline & TF4 & 0.84 & & \\
\hline \multirow{3}{*}{$\begin{array}{l}\text { Training and } \\
\text { Development (TSD) }\end{array}$} & TSD1 & 0.655 & \multirow{3}{*}{0.824} & \multirow{3}{*}{0.612} \\
\hline & TSD2 & 0.822 & & \\
\hline & TSD3 & 0.856 & & \\
\hline \multirow{12}{*}{$\begin{array}{l}\text { Woman } \\
\text { (WEMP) }\end{array}$} & WEMP1 & 0.65 & \multirow{12}{*}{0.900} & \multirow{12}{*}{0.646} \\
\hline & WEMP2 & 0.61 & & \\
\hline & WEMP3 & 0.72 & & \\
\hline & WEMP4 & 0.71 & & \\
\hline & WEMP5 & 0.58 & & \\
\hline & WEMP6 & 0.64 & & \\
\hline & WEMP7 & 0.66 & & \\
\hline & WEMP8 & 0.68 & & \\
\hline & WEMP9 & 0.62 & & \\
\hline & WEMP10 & 0.65 & & \\
\hline & WEMP11 & 0.66 & & \\
\hline & WEMP12 & 0.68 & & \\
\hline
\end{tabular}

Source: Researcher

Table-2 Heterotrait-Monotrait Ratio (HTMT)

\begin{tabular}{lllll}
\hline & $\mathbf{1}$ & $\mathbf{2}$ & $\mathbf{3}$ & $\mathbf{4}$ \\
Educational Facilities & & & & \\
Technology Facilitation & 0.451 & & \\
Training and Skills Development & 0.612 & 0.510 & & \\
Woman Empowerment & 0.773 & 0.551 & 0.730 & \\
\hline
\end{tabular}


As shown in table-2 in the study as per suggestion of Hair (2006) assess the discriminant validity through HTMT. All the values are below 0.85 so, the discriminant validity has been established (Henseler, Ringle, \& Sarstedt, 2015).

By employing software named Smart PLS3.2.9 by Henseler et al. (2015) the structural equation model (SEM) was performed next to ascertain the strength of model. For that bootstrapping technique with 5000 resamples Ringle et al. (2015) employed using Bias-Corrected and Accelerated $(\mathrm{BCa})$. The parameters used in the this study to analyze the structural model is significance of path coefficient (t-value), estimation of path-coefficient $(\beta)$, confidence interval, effect size $\left(\mathrm{f}^{2}\right)$ as by Hair et al. (2017) recommended.

Table-3 Significant testing results of the structural model path coefficients

\begin{tabular}{|c|c|c|c|c|c|c|c|c|c|c|}
\hline $\begin{array}{l}\text { Hypot } \\
\text { hesis }\end{array}$ & Relationship & $\begin{array}{l}\text { Standard } \\
\text { Beta }\end{array}$ & $\begin{array}{l}\text { Standard } \\
\text { error }\end{array}$ & $\mathbf{t}$-value & $\begin{array}{l}\mathbf{p}- \\
\text { value }\end{array}$ & LCI & UCI & $\mathbf{f}^{\mathbf{2}}$ & Effect size & $\begin{array}{l}\text { Supporte } \\
\mathbf{d}\end{array}$ \\
\hline $\mathbf{H}_{\mathbf{1}}:$ & EF $\rightarrow$ WEMP & 0.300 & 0.01809 & 16.583 & 0.000 & 0.265 & 0.335 & 0.05 & Small & Yes \\
\hline $\mathbf{H}_{\mathbf{2}}:$ & TF $\rightarrow$ WEMP & 0.250 & 0.01265 & 19.765 & 0.000 & 0.225 & 0.275 & 0.07 & Small & Yes \\
\hline $\mathbf{H}_{3}:$ & TSD $\rightarrow$ WEMP & 0.290 & 0.02154 & 13.466 & 0.000 & 0.248 & 0.332 & 0.16 & Medium & Yes \\
\hline
\end{tabular}

Source: Researcher

Table-3 indicates that EF $\rightarrow$ WEMP (Standard Beta=0.30, t-value 16.583, p-value <0.05) (Hahn \& Ang, 2017) with CI [0.265, 0.335] not overlapping zero (Hair et al., 2017). Hence, signifying the acceptance of $\mathrm{H}_{1}$. The association between EF and WEMP has small effect in this study, $\mathrm{f}^{2}=$ 0.05(Preacher \& Hayes, 2008).

Above table-3 indicates that TF $\rightarrow$ WEMP (Standard Beta $=0.250$, t-value 19.765, p-value $<0.05$ ) (Wong, 2013) with CI [0.225, 0.275] not overlapping the zero (Hair et al., 2017) which demonstrating the acceptance of $\mathrm{H}_{2}$. This relationship has small effect size in current study, $\mathrm{f}^{2}=$ 0.07(Preacher \& Hayes, 2008).

Table-3 demonstrating the TSD $\rightarrow$ WEMP (Standard Beta $=0.290, \mathrm{t}$-value 13.466, $\mathrm{p}$-value $<0.05$ ) (Wong, 2013) with CI [0.248, 0.332] not overlapping the zero (Hair et al., 2017). Hence, signifying the acceptance of $\mathrm{H}_{3}$. The association between TSD and WEMP has medium effect in this study, $\mathrm{f}^{2}=0.16$ (Preacher \& Hayes, 2008).

\section{Discussion}

By investigating the hypothesized association using SEM, it was identified that Educational facilities positively related to woman empowerment This authenticates with previous conclusions, which shows a positive connection between educational facilities to woman empowerment. Endorsing the comparable relationship (Wong, 2013) indicated education is the key factor for empowerment, prosperity, development and well-being of women. By providing appropriate education help developing and boosting up strength and confidence in woman. Economically strong educated women in Pakistan were more empowered to make reproductive and household decisions. Correspondingly (Chaudhry \& Rahman, 2009) endorsed the similar outcome as women are empowered with the provision of all by help academic resources in order to attain awareness and establishing self-belief. While (Tunio, 2015) empowering women is to give women the right. Women can have equal right to contribute in academics, society and the 
economy. Although there are significant gender disparities in academics, throughout the whole country, but some sector are much poorer than others. The second hypothesis was concerned about Technology Facilitation positively related to woman empowerment. Findings suggest academic and non-academic education in rural Bangladesh led to positive and significant influences on women empowerment (Umair, 2016). Relatedly (parveen, 2016) mentioned Technology Facilitation is equally essential for empowering woman in society . It improves standard of living, It opens up doors for new opportunities to do business or work. Technology can improve productivity, and uplift financial autonomy of women. While the last hypothesis Training and Skills Development positively related to woman empowerment. The literature confirmed the similar outcome appropriate training, support and skill development initiatives are desired to strengthen woman. As due to lots of limitations, restrictions and financial and moral constraints or cultural norms they are unable to uplift their strand of living of themselves and their family (Mulhim, 2013) while in Pakistanis context (Okolie et al., 2020) validated that Rural women as well as urban woman faces lots of difficulties in equipping themselves with modern ways of operations. Ultimately it boosts up their confidence and result dynamics in their personality and increase growth.

\section{Conclusion}

It was concluded that Pakistani women make enormous contributions to economies, whether in businesses, on farms, as entrepreneurs or employees. Women's empowerment is essential to be encouraged to feel strong by ensuring them that they can do all and all that they intend to do. Presently there are inadequate educational facilities, technology facilitation and appropriate training and skills enhancement opportunities for Pakistani woman. In this regard, suitable schooling, formal and non-formal modes for developing competences, boosting up the skills though knowledge sharing, training, seminars, workshops will significantly groom and progress Pakistani woman. Economically strong educated women in will be more empowered to make productive decisions. Academician, policy makers and Leaders of organizations must note this fact; initiatives to upsurge women's empowerment set a straight path towards gender equality, eradication of poverty and inclusive economic growth for the country and at worldwide level.

\section{References}

Ahmed, A., Wadood, A., \& Mohammad, N. (2020). Tracer Study of Socio-economic and demographic Impacts of Technical and Vocational Education and Training (TVET) for Women in Baluchistan.

Ahmed, M., Zameer, M., Verman, S. K., \& Godiyal, S. (2021). Educational Needs and Training for Women Empowerment in India. TRANS-KATA: Journal of Language, Literature, Culture and Education, 1(2), 58-67.

Ali, R. (2015). Education and women Empowerment in Northern Pakistan: Tracing Accomplishment and Predicmants. Research of humanities and social Services, 12.

ambreen, M. (2013). economic empowerment of women influecing family structures :a case study of village Dasha,District faisalabad.

Chaudhry, I. S., \& Rahman, S. (2009). The impact of gender inequality in education on rural poverty in Pakistan: an empirical analysis. European Journal of Economics, Finance and Administrative Sciences, 15(1), 174-188.

Correa-fernandes. (2015). gender and development :A literature reveiw. journal of advocacy ,research and education.

Faul, F., Erdfelder, E., Lang, A.-G., \& Buchner, A. (2007). G* Power 3: A flexible statistical power analysis program for the social, behavioral, and biomedical sciences. Behavior Research Methods, 39(2), 175-191.

Fernandes, C. (2015). Gender and Development: A literature review. GIRE - Repositorio digital, 128-134. 
Gaertner, K. N., \& Nollen, S. D. (1989). Career experiences, perceptions of employment practices, and psychological commitment to the organization. Human relations, 42(11), 975-991.

Hahn, E. D., \& Ang, S. H. (2017). From the editors: New directions in the reporting of statistical results in the Journal of World Business. Journal of World Business, 52(2), 125-126. doi:https://doi.org/10.1016/j.jwb.2016.12.003

Hair, J. F. (2006). Black, WC/Babin, BJ/Anderson, RE \& Tatham, RL (2006): Multivariate Data Analysis. Auflage, Upper Saddle River.

Hair, J. F., Black, W. C., Babin, B. J., Anderson, R. E., \& Tatham, R. L. (2006). Multivariate data analysis (Vol. 6). In: Upper Saddle River, NJ: Pearson Prentice Hall.

Hair, J. F., Sarstedt, M., Hopkins, L., \& Kuppelwieser, V. G. (2014). Partial least squares structural equation modeling (PLS-SEM). European Business Review.

Hair, J. F., Sarstedt, M., Ringle, C. M., \& Gudergan, S. P. (2017). Advanced issues in partial least squares structural equation modeling: Sage Publications.

Henseler, J., Ringle, C. M., \& Sarstedt, M. (2015). A new criterion for assessing discriminant validity in variance-based structural equation modeling. Journal of the academy of marketing science, 43(1), 115-135. doi:https://doi.org/10.1007/s11747-014-0403-8

Khan, M., \& Zerby, J. (1981). The socioeconomic position of Pakistan in the third world. The Pakistan Development Review, 347-365.

Memon, G. R. (2007). education in pakistan :the key issues ,problems and the new challenges. journal of management and social sciences, 15.

Mulhim. ( 2013). the current use if ICT by noivice female teachers in Saudi primary schools and theirpercieved training needs.

News, T. (2020). Economic Survey reveals Pakistan's literacy rate increased to $60 \%$. Retrieved from https://www.thenews.com.pk/latest/671198-economic-survey-reveals-pakistansliteracy-rate-increased-to-60

Ojha. (2016). Role of education in empowering rural women for sustaniable development in india. international journal of applied reseach.

Okolie, U. C., Nwajiuba, C. A., Binuomote, M. O., Osuji, C. U., Onajite, G. O., \& Igwe, P. A. (2020). How careers advice and guidance can facilitate career development in technical, vocational education, and training graduates: The case in Nigeria. Australian Journal of Career Development, 29(2), 97-106.

parveen. (2016). Retrieved from

Plax, T. G., Kearney, P., \& Downs, T. M. (1986). Communicating control in the classroom and satisfaction with teaching and students. Communication Education, 35(4), 379-388.

Preacher, K. J., \& Hayes, A. F. (2008). Asymptotic and resampling strategies for assessing and comparing indirect effects in multiple mediator models. Behavior research methods, 40(3), 879-891. doi:https://doi.org/10.3758/BRM.40.3.879

Rehman, A., Jingdong, L., \& Hussain, I. (2015). The province-wise literacy rate in Pakistan and its impact on the economy. Pacific Science Review B: Humanities and Social Sciences, 1(3), 140-144.

Ringle, C. M., Wende, S., \& Becker, J.-M. (2015). SmartPLS 3. Boenningstedt: SmartPLS $\mathrm{GmbH}$.

Saeeda Shah, A. s. ( 2012). Girl education in rural pakistan. international journakl of sociology of education.

Spreitzer, G. M. (1995). Psychological empowerment in the workplace: Dimensions, measurement, and validation. Academy of Management Journal, 38(5), 1442-1465.

Taylor, S., \& Todd, P. A. (1995). Understanding information technology usage: A test of competing models. Information Systems Research, 6(2), 144-176.

Tunio, S. ( 2015). An analysis of the state of female education in sindh and riole of television in increasing literacy rate. journal of south asain development, 10. 
Umair, S. (2016). education and ampowerment of the women in rural areas of balochistan .the views of baloch tribal men. international journal of humanities and social scineces, 10.

Wong, K. K.-K. (2013). Partial least squares structural equation modeling (PLS-SEM) techniques using SmartPLS. Marketing Bulletin, 24(1), 1-32.

Yerriswamye, D. (2016). roel of women empowerment through education. 